\title{
Simple extraction and membrane purification process in isolation of steviosides with improved organoleptic activity
}

\author{
Adari Bhaskar Rao ${ }^{1 *}$, Ernala Prasad ${ }^{1}$, Goka Roopa $^{1}$, Sundergopal Sridhar ${ }^{2}$, \\ Yerrapragada Venkata Lakshmi Ravikumar ${ }^{2 *}$ \\ ${ }^{1}$ Organic Chemistry Division, Indian Institute of Chemical Technology, Hyderabad, India \\ ${ }^{2}$ Chemical Engineering Division, Indian Institute of Chemical Technology, Hyderabad, India \\ Email: *adarirao2002@yahoo.co.in
}

Received 14 May 2012; revised 25 June 2012; accepted 7 July 2012

\begin{abstract}
In recent years there has been increasing demand for natural non-nutritive high intensity sweeteners with low-calorie value as an alternative to sucrose. Extracts of the leaves of Stevia rebaudiana (Bertoni), have been known for their sweet taste. Steviosides and rebaudioside- $A$ are the two major diterpenoid glucosides components present in the leaf extracts of the stevia, these glycosides are $\mathbf{3 0 0}$ times sweeter than sugar and also exhibits wide therapeutic activity. The conventional methods of isolation of steviosides involve long extraction and purification procedures; therefore optimization of product yields is a challenging problem. The present study, establishes a new improvised process of extraction of steviosides from the stevia leaves in which the dry treated leaves were grounded, defatted, and extracted through pressurized hot water extractor (PHWE), followed by purification and concentration of the sweet glycosides through ultra (UF) and nano (NF) membrane filtration in obtaining high (98.2\%) purity steviosides. This process established "green" method for isolation of high quality steviol glycosides, with improved final yield is $10.1 \%$ from $11 \%$ of crude leaf extract and observed the improved organoleptic and biological activity (antioxidant). Thus the method confirms a simple, in-expensive and eco-friendly process in obtaining pure steviosides.
\end{abstract}

Keywords: Steviol Glycosides; Membrane-Filtration; Natural-Sweetener; Antioxidant; In-Expensive

\section{INTRODUCTION}

Dietary and health demands are continuing to expand the market for sweeteners in two distinct areas one in specifically for the low calorie/dietetic segment, while the

${ }^{*}$ Corresponding author. other is as an alternative to sugar and other nutritive sweeteners (i.e. corn syrup, fructose, glucose) [1]. Recently, there is an increasing demand for low calorie natural sweeteners as a substitute for sucrose and other synthetic sweeteners such as saccharine and aspartame. Stevia a perennial plant species commonly called as "sweet herb" is gaining significant importance as a natural sweetner in different parts of the world and is expected to develop into a major source of high potency sweetener for the growing natural food market [2-4]. Steviol glycosides are natural diterpene glycosides extracted from the leaves of Stevia rebaudiana Bertoni. (Family-Asteraceae) possessing a 250 - 300 times higher sweetening property than sucrose, and they also used in treatment of patients suffering from carbohydrate metabolic diseases such as diabetes mellitus, obesity, hypertension and stimulates cell regeneration. Thus the steviol glycosides are also widely used in food, beverage, medicine, wine making cosmetics and other food/chemical industry [5-7]. Despite wide therapeutic application of these sweet glycosides, its uses are limited for human consumption (food and pharmaceutical) due to its after taste bitterness, astringency and grassy taste; associated with the presence of some un-known glycosides and other alkaloid impurities [8]. Thus, the quality and taste of the commercial stevioside product depends on the percentage/proportion of the steviol glycosides in the product.

Traditional separation and isolation process of natural products from plant extracts normally use different techniques but still it remains a mystery in isolation of water soluble natural-compounds. There are abundant published/patented literature in extraction and purification process of steviosides based on solvent, solvent plus a decolorizing agent, selective precipitation by metallic ions, supercritical fluid extraction and purification by adsorption and column chromatography, ion exchange resin, ultra and nano membrane process [9-12]. The recent development of various membrane-based techniques 
for the purification of valuable natural products covers utilization of microfiltration, ultrafiltration and nanofiltration membrane techniques, either carried out singly or coupled with other separation techniques, in order to achieve purification process of natural products to improve the biological activity [13-16].

The available extraction process require long and complex extraction processes steps, high temperatures and no information about the effects of the extraction methods on the contents of steviosides. The long isolation procedures of steviol glycosides known to produce noxious residues and biter alkaloids harmful to the human health $[17,18]$. Some of the recent stevioside isolation methodologies are expensive and are energy intensive process in obtaining pure steviol glycosides' [9-11, 19]. Therefore, a simple, inexpensive and environmental friendly procedure in isolation of highly purified steviol glycosides is present day challenging problem [20-23]. Oxygen free radicals and other reactive oxygen species can cause oxidative injury to living organisms and thus play an important role in many lifestyle related diseases such arthritis, tissue injury, atherosclerosis, cancer and neurodegenerative diseases as well as ageing process [24-26].

Although several synthetic antioxidants, such as butylated hydroxyl anisole (BHA) and butylated hydroxyl toluene (BHT), are commercially available, these synthetic antioxidants are quite unsafe and are toxic to humans [27]. There is a growing interest in natural antioxidants found in plants because of the world wide trend towards the use of natural additives in food and cosmetics. Natural plant-based anti oxidants especially phenolics and flavonoids have gained importance in therapeutic potential and has been exploited commercially either as antioxidant additives or as nutritional supplements [28-30].

Therefore, the present study is on development of simple, inexpensive processes by minimizing unit operations and chemical usage of solvents and subsequently refining the isolation of steviosides by removing the impurities of after taste for additional improvement of taste profile and anti-oxidant potential of steviosides isolated from the aqueous extract of $S$. rebuadiana leaves.

\section{EXPERIMENTAL}

\subsection{Materials}

Leaves: Stevia rebaudiana bertoni leaves were obtained from Sigma-Aldrich Chemicals USA S5381-batch \#100F0417. Stevioside 97\%: The standard stevioside 97\% (HPLC) was purchased from Sigma chemicals USA.

All the chemicals and solvents used in the process were of commercial solvents and were glass distilled. The membrane filtration was carried out using hollow fiber ultrafiltration (HF-UF) membrane of 30,000 molecular weight cut off (MWCO) the length of spiral wound module and hydrophilized polyamide (HPA) nanofiltration (NF) membrane of 250 MWCO were purchased from M/s Permionics Membranes India Ltd., Vadodara, India.

\subsection{Methods}

\subsubsection{Analytical Methods}

The concentration of steviosides present in the leaf extracts were quantified by high performance liquid chromatography (HPLC) using Waters spherisorb $\mathrm{NH}_{2}$ analytical column $(250 \mathrm{~mm} \times 4.6 \mathrm{~mm}$, particle size $5 \mu \mathrm{M})$, elution solvent used was acetonitrile: $0.1 \mathrm{mM}$ Na-phosphate buffer $\mathrm{pH}-5$ (85:15) in isocratic mode; with flow rate of $1.0 \mathrm{~mL} \cdot \mathrm{min}^{-1}$, column temperature maintained at $27^{\circ} \mathrm{C}-28^{\circ} \mathrm{C}$, and $\mathrm{UV}$ detection was adjusted at $210 \mathrm{~nm}$ [31,32]. In LC-Mass analysis of steviosides the isocratic solvent system acetonitrile: $0.1 \mathrm{mM}$ sodium-phosphate buffer $\mathrm{pH}-5(60: 40)$ with flow rate of $1.0 \mathrm{~mL} \cdot \mathrm{min}^{-1}$ was used.

The structure of the purified stevioside isolated was confirmed by $1 \mathrm{H}-\mathrm{NMR}$ and LC-MASS spectral studies and compared with standard stevioside obtained from Sigma Chemicals USA.

\subsubsection{Isolation and Purification of Steviosides}

The leaves $(5 \mathrm{Kg})$ of Stevia rebaudiana were initially air dried at $50^{\circ} \mathrm{C}$ and treated with non polar organic solvent to remove color pigments and waxy material present on the surface of stevia leaves. Thus obtained leaves were powdered to $20-30 \mathrm{~mm}$ mesh size and steviosides were extracted in aqueous solution (1:10) adjusted to $\mathrm{pH} \mathrm{3}$, at $60^{\circ} \mathrm{C}$, with agitation. On incubation for 6 hours the extract was subjected to pressurized hot water extractor (PHWE) operating at optimized conditions of $100 \mathrm{kPa}$ pressure at temperatures of $100^{\circ} \mathrm{C}-110^{\circ} \mathrm{C}$ for 10 minutes, for extraction of steviosides. Thus, obtained crude extract was cooled and filtered solution was adjusted to $\mathrm{pH} 10$ by adding $0.1 \mathrm{~N}$ sodium hydroxide and heated to $60^{\circ} \mathrm{C}$ for one hour, the precipitate formed was filtered and the stevioside rich solution was neutralized to $\mathrm{pH} 7$ by adding dilute acid $(0.1 \mathrm{~N} \mathrm{HCl})$. The crude solution rich in stevioside was passed through ultrafiltration (UF) membrane of $30 \mathrm{kDa}$, molecular weight cut-off (MWCO), operating at a feed pressure of experimental conditions. The concentration of stevioside present in the extracts was determined $200-500 \mathrm{kPa}$, at room temperature. This process removes cell debris and helps in clarification of the leaf extract, in obtaining a clear solution containing sweet steviol glycosides. The UF membrane unit operation results in retaining leaf carotenoid pigments $(70 \%$ $80 \%$ ); quantified through spectrophotometer, as des- 
cribed in AOAC, 2000 [33]. The obtained filtrate was passed through nanofiltration membrane (NF) with a MWCO ranging of $250 \mathrm{Da}$, operated at a trans membrane pressure of $1500 \mathrm{kPa}$ at a room temperature to concentrate the product stevioside in the retentate by removing $80 \%-90 \%$ of water through permeate. Thus obtained stevioside rich solution was treated with active animal charcoal $(20 \%)$ and filtered through ciliate $(5 \%)$ for to obtain a clear solution enriched with steviosides, this on spray drying gave a white stevioside powder. All the operating conditions carried out by UF/NF membrane process in isolation and purification steviosides from stevia leaves were carried at optimum by HPLC. The structure of steviosides were confirmed by NMR and mass spectral studies (LC-Mass chromatogram) and compared with standard stevioside (Figure 1).

\subsubsection{Ultrafiltration and Nanofiltration Procedures}

The clarification of the stevia extract (30 L solution) was carried out using ultrafiltration membrane (HF-UF $30 \mathrm{kD}$ membrane) operated in batch mode with complete recycle of reject at a constant feed rate of $17 \mathrm{~L} / \mathrm{min}$ were $23 \mathrm{~L}$ of permeate, which gives high flux without compromising on the quality of the stevioside present in the permeate [16]. The permeate enriched in the steviol-glycosides (20 L) was feed to HPA-250 nanofiltration membrane to collect enrich stevioside in the reject and the obtained water solution in the permeate $(14 \mathrm{~L})$ was free from sweet glycosides. The enriched stevioside reject was passed through animal charcoal and cellite to remove colour of the stevia extract and the impurities of bitter taste. Thus obtained enrich concentrated stevia extract was spray dried to obtain powdered stevioside.

The effect of pressure in separation stevioside and life of the membrane used for filtration process was studied as described in our earlier studies [34].

\subsubsection{Determination of Stevioside Rejection,} Permeate Flux and Percentage Water Recovery In UF and NF membrane processes the separation performance of the membrane is denoted in terms of $\%$

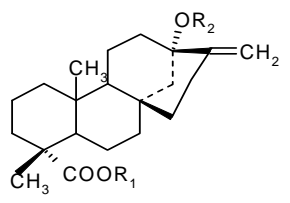

\begin{tabular}{cccc}
\hline S. No & Compound name & $\mathrm{R}_{1}$ & $\mathrm{R}_{2}$ \\
\hline 1 & Steviol & $\mathrm{H}$ & $\mathrm{H}$ \\
2 & Stevioside & $\beta$-glucose & $\beta$-glucose- $\beta$-glucose $(2-1)$ \\
3 & Rebaudioside A & $\beta$-glucose & $\begin{array}{c}\beta \text {-glucose- } \beta \text {-glucose }(2-1) \\
\beta \text {-glucose }(3-1)\end{array}$ \\
\hline
\end{tabular}

Figure 1. Structures of steviosides and related sweet glycosides. rejection of solute which was calculated as given in Sridhar et al., 2000 [34].

$$
\% R=\left(1-C_{P} / C_{f}\right) \times 100
$$

where the $C_{p}$ is amount of the stevioside in the permeate, $C_{f}$ is the amount of the stevioside in the feed.

The flux $(J)$ is the volume of the permeate $(V)$ collected per unit membrane area per unit time $(t)$ :

$$
J=V / A t
$$

The approximate osmotic pressure $\Delta \pi$ (bar) is determined from the following equation:

$$
\Delta \pi=v_{i} c_{i} R T
$$

where $c_{i}$ is the concentration of $\operatorname{TDS}(\sim \mathrm{NaCl})$ in $\mathrm{mol} \cdot \mathrm{dm}^{-3}, v_{i}$ is the number of ions formed when the solute dissociates, $\mathrm{R}$ is the universal gas constant $(83.133$ $\left.\mathrm{dm}^{3} \cdot \mathrm{bar} \cdot \mathrm{kmol}^{-1} \cdot \mathrm{k}^{-1}\right)$ and $\mathrm{T}$ is the absolute temperature (301 k).

For clarification of the stevia extract an absorbance analysis was carried out

$$
\% \text { clarification }=\left\{1-\mathrm{A} \text { after } / \mathrm{A}^{\prime \prime} \text { before }\right\} \times 100 .
$$

Percentage (\%) steviosides (stevioside or rebaudioside) recovered after the purification process, were calculated.

$$
\begin{aligned}
& \text { Steviosides yield } \% \\
& =\frac{\text { Concentration of stevioside in the crude extract }}{\text { Concentration of stevioside in the permeate }} \times 100
\end{aligned}
$$

where, the subscripts "after" and "before" mean after and before the clarification, respectively. Optical absorbencies measured at 420 or $670 \mathrm{~nm}$ correspond to color or turbidity analysis, respectively. The concentration of steviol glycoside recovered after the purification process, were quantified through HPLC.

\subsubsection{Sensory Evaluation}

The relative sweetness of steviol glycosides was compared in relation to standard sucrose solution. The organoleptic sensory evaluation for steviosides present in stevia extract and FCPS-(final crystallized product of stevia leaf extract) was carried out by comparing with sucrose solution $2 \%$ as a reference standard, taking its sweetness value as 100 , which give a direct quantitative measure of the subjective intensity of stevioside sweetness [35-38].

\subsubsection{Determination of Antioxidant Activity Different Radical Scavenging Activities}

Steviol glycosides obtained from stevia leaves promote wide range of physiological activities like cardiovascular, anti cancer, hyperglycemia and also influence in reducing hypertension [38]. Superoxide radical is known to be 
very harmful to cellular components as a precursor of the more reactive oxygen species, contributing to tissue damage and various diseases [39]. Superoxide scavengers and their capacity to scavenge superoxide may contribute to their anti oxidant activity. A large number of phyto chemicals, phenols, flavonoids are among the most potent and therapeutically useful bioactive molecules, providing health benefits associated with reducing of oxidative injury to living organism $[40,41]$. The traditional use of leaves of $S$. rebaudiana as natural antioxidants with consequent health benefits has to be confirmed by battery of antioxidant assays.

To evaluate the antioxidant activity or super oxide radical scavenging activity of the steviol glycosides present in the extract of stevia following assays were studied 1) free radical scavenging capacity assay by DPPH $(1,1-$ Diphenyl-2-picrylhydrazyl) method; 2) hydroxyl superoxide radical and 3) nitric oxide radical assay were carried out using standard methods [42]. The results obtained were compared with that of known anti-oxidants samples like green tea and ascorbic acid.

\section{Statistical Analysis}

The results were analyzed by two-way ANOVA followed by Bonferroni post tests. The results were processed by GraphPad Prism version 5.0. Results were found statistically significant $(\mathrm{P}<0.05)$.

\section{RESULTS AND DISCUSSIONS}

This study high lights development of a rapid, improvised and effective methodology in isolation and purification of sweet glycosides, from the leaves of Stevia rebaudiana. The process involves combined use of pressurized hot water extraction, followed by ultra-filtration and nano-filtration to obtain high quality steviosides from the leaves of the stevia. The initial pretreatment of stevia leaves with hexane, results in removing color pigments and waxy plant material and helps in subsequent process of clarification of the extract. The total pigments (carotenoids) extracted were found to be 19 $22 \mathrm{mg} / 100 \mathrm{~g}$ of dry stevia leaves [43]. After preliminary discoloration the powdered stevia leaves were subjected to water extraction in a pressure reactor to obtain stevioside rich extract (CSEA-crude stevia leaf extract after autoclave). It was observed that the rate of extraction of stevia was higher at $\mathrm{pH} 3$ during the process of extraction. Thus obtained extract was subjected to multi stage ultra and nano membrane filtration process to remove suspended particles, high molecular weight impurities and undesirable bitter compounds, without any loss of steviosides/or in the permeate (decline in non-glycoside peaks in HPLC chromatogram) Table 1. Thus indicating reasonably high permeation rates and no significant
Table 1. Comparative performance of UF and NF membranes in concentration and purification of steviosides $(7 \%-8 \%)$ present in Stevia rebaudiana + .

\begin{tabular}{|c|c|c|c|}
\hline S. No & Parameters & Ultra-filtration & Nano-filtration \\
\hline 1 & Feed pressure & 10 & 20 \\
\hline 2 & $\begin{array}{l}\text { Stevioside in feed } \\
\qquad(\mu \mathrm{g} / \mathrm{ml})\end{array}$ & 09 & 90 \\
\hline 3 & $\begin{array}{c}\text { Steviosides in } \\
\text { permeate }(\mu \mathrm{g} / \mathrm{ml})\end{array}$ & 6.5 & 3.0 \\
\hline 4 & Pigments (\%) & $80-90$ & 05 \\
\hline 5 & Flux $\left(1 / \mathrm{m}^{2} \mathrm{~h}\right)$ & 24 & 32 \\
\hline
\end{tabular}

Values given based on mean of three studies.

fouling of membranes was observed during the process of filtration. The stevioside enriched permeate was filtered through active animal charcoal and celate to obtain golden yellow color solution containing steviol glycosides which on spray drying gave a pure white product $(98 \%)$ of steviol-glycosides.

\subsection{Effect of Pressure}

From the results the increase feed pressure in NF membrane from $200-600 \mathrm{psi}$, the increase flux from $25.2 \mathrm{~L}$ to $39.3 \mathrm{lit} / \mathrm{m}^{2}$. Hr was observed, whereas the permeate conductivity reduced from 0.48 to $0.26 \mathrm{mS} / \mathrm{cm}$ as shown in Figure 2. The recovery of water was maintained constant at $60 \%-80 \%$ for all the operating pressures. The increase in pressure would obviously is due to greater driving force for transport of the water molecules leading to a rise in flux. It is well known that by solution diffusion mechanism, the hydrophilic NF membrane allows more and more water molecules to pass through due to preferential sorption of water on the membrane surface [44]. Thus the smaller molecular size (MW $=18)$ of the water molecules would therefore exhibit higher diffusivity compared to the much larger stevioside molecules; resulting in $100 \%$ rejection of stevioside throughout the range of feed pressure studied.

\subsection{Membrane Fouling and Its Control}

The UF /NF membranes would be especially prone to biological fouling since aqueous stevia solution gathers fungal growth within two days time [45]. For a prolonged life of the filtration membrane it is necessary to wash the membrane thoroughly washed with deionized water followed by $2 \%(\mathrm{w} / \mathrm{v})$ citric acid solution to remove metal salt precipitates formed due to presence of in organics in the feed solution. Every alternate week, washing with $1 \%(\mathrm{w} / \mathrm{v})$ solution of tetra sodium EDTA, a chelating agent is necessary to remove organic foul ants and silt and the membrane is finally stored in a $1 \%(\mathrm{w} / \mathrm{v})$ 


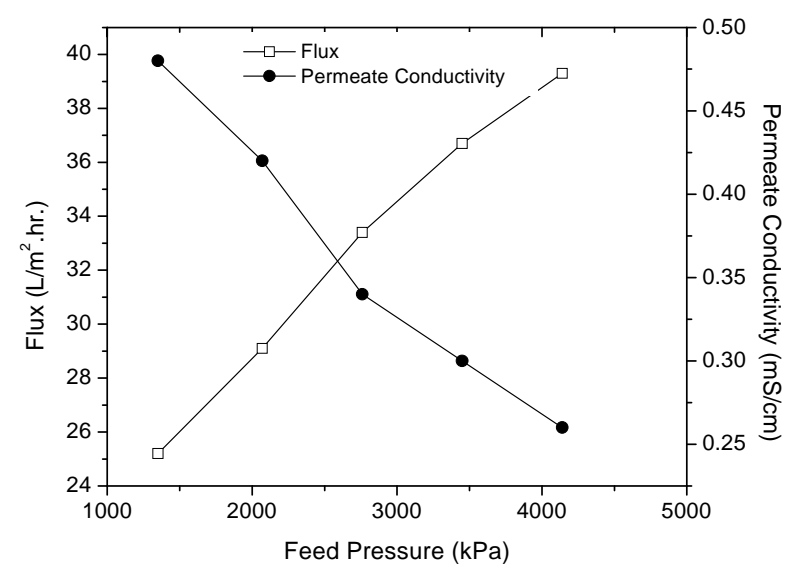

Figure 2. Effects of feed pressure on permeate flux and conductivity at constant water recovery by nanofiltration membrane (values expressed were average of three determinations).

sodium metabisulfite solution to prevent biological fouling. The membrane show longer half life, without membrane fouling when compared to other existing methods available

The conceptual flow diagram Figure 3 show the process of extraction, isolation and purification steps that produce a high purity steviosides $94 \%-98 \%$ with recovery yield of sweet steviol glycosides from the stevia leaves in the range of $(90 \%-95 \%)$, as confirmed through HPLC, LC-Mass and NMR analysis Figures 4 and $\mathbf{5}$.

\subsection{Sensory Evolution}

It was observed that the steviosides isolated through the multistage membrane filtration has improved sweetening potency and taste profile. This may be due to the removal of glycoside impurities or bitter alkaloids responsible for after taste present in the stevia extracts Table 2 [14].

\subsection{Antioxidant Activity Assay}

Natural antioxidants that are present in herbs and spices are responsible for inhibiting or preventing the deleterious consequences of oxidative stress. It is well known that the stevia extracts contain flavonoids or phenolic compounds that scavenge the free radicals, promote wide range of physiological activities $[46,47]$. The free radical scavenger activity for three different samples of stevia leaf extracts (SEHW, CSEA, and FCPS) were compared with the reference sample aqueous extract of green tea leaves (Camellia sinensis Linn.) prepared by infusions of $1 \mathrm{~g}$ of green tea brewed for $5 \mathrm{~min}$ with $100 \mathrm{~mL}$ of boiling water, and with standard ascorbic acid of equal concentration to that of Stevioside samples $(5 \mu \mathrm{g} / \mathrm{ml})$. From the results as shown in Figure 6 the percentage inhibition of DPPH free radical scavenging activity for green tea was $7.3 \%$ and for standard ascorbic acid it was $86.5 \%$, where as for the three stevia extracts it was $21.5 \%$; $40.25 \%$; $39.8 \%$ respectively. All the three stevia sample extracts have shown increased in vitro antioxidant activity when compared with green tea extract tested; similar results were obtained with other two free radical assay methods.

This study confirms a simple advantageous methodology of extraction and purifications process of steviosides using multistage UF and NF membrane filtration operating with higher flux and flow rates, at room temperature. The UF and NF membranes used show longer half life, without membrane fowling when compared other existing methods available. Thus, the method established show the isolation of high purity steviosides free from impurities of bitterness, with improved taste and anti-oxidant activity, without presence of any impurities and obnoxious residues in an eco-friendly condition.

\section{CONCLUSION}

Steviosides are major low-calorie diterpene steviol glycosides present in the leaves of Stevia rebaudiana. They are widely used as natural low calorie sweetener for diabetic patients. The long extraction and optimization

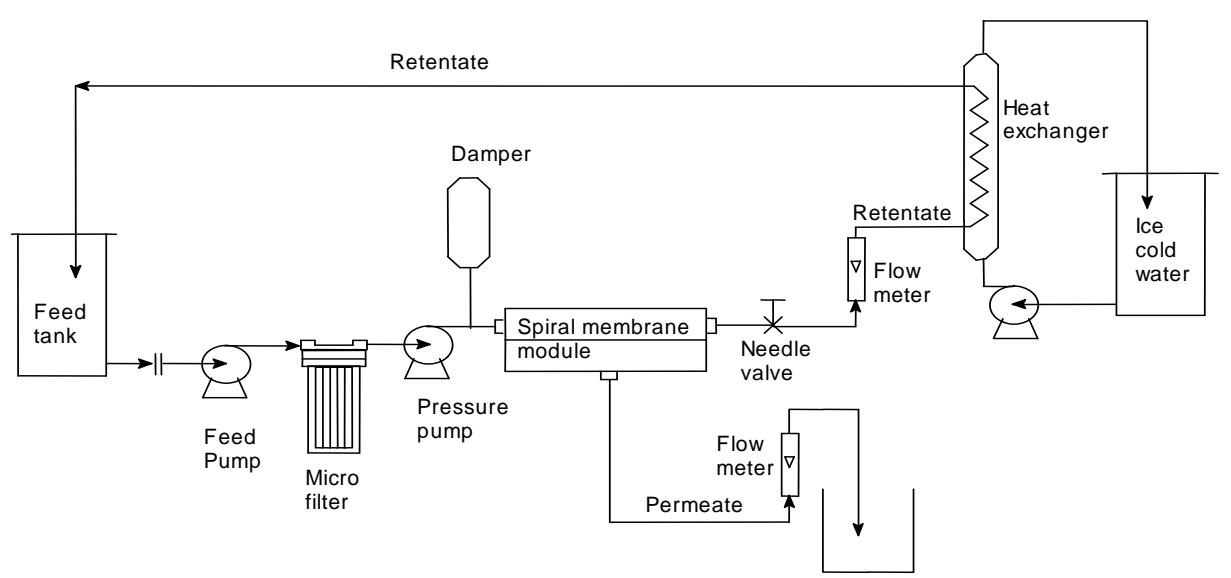

Figure 3. Schematic view of ultra filtration/nano filtration experimental mini pilot plant. 


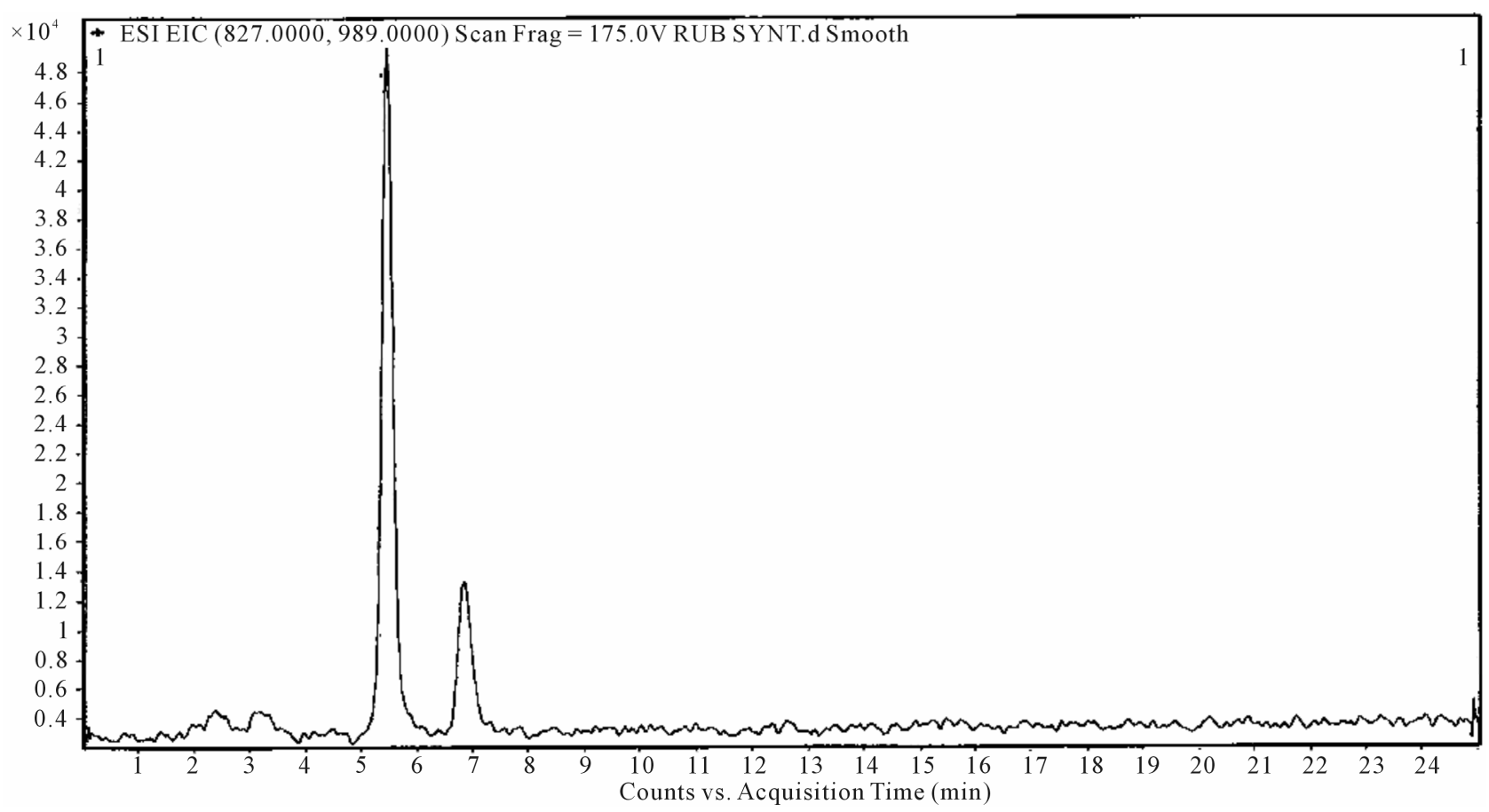

Figure 4. ESI-LC mass spectra-pure stevioside.

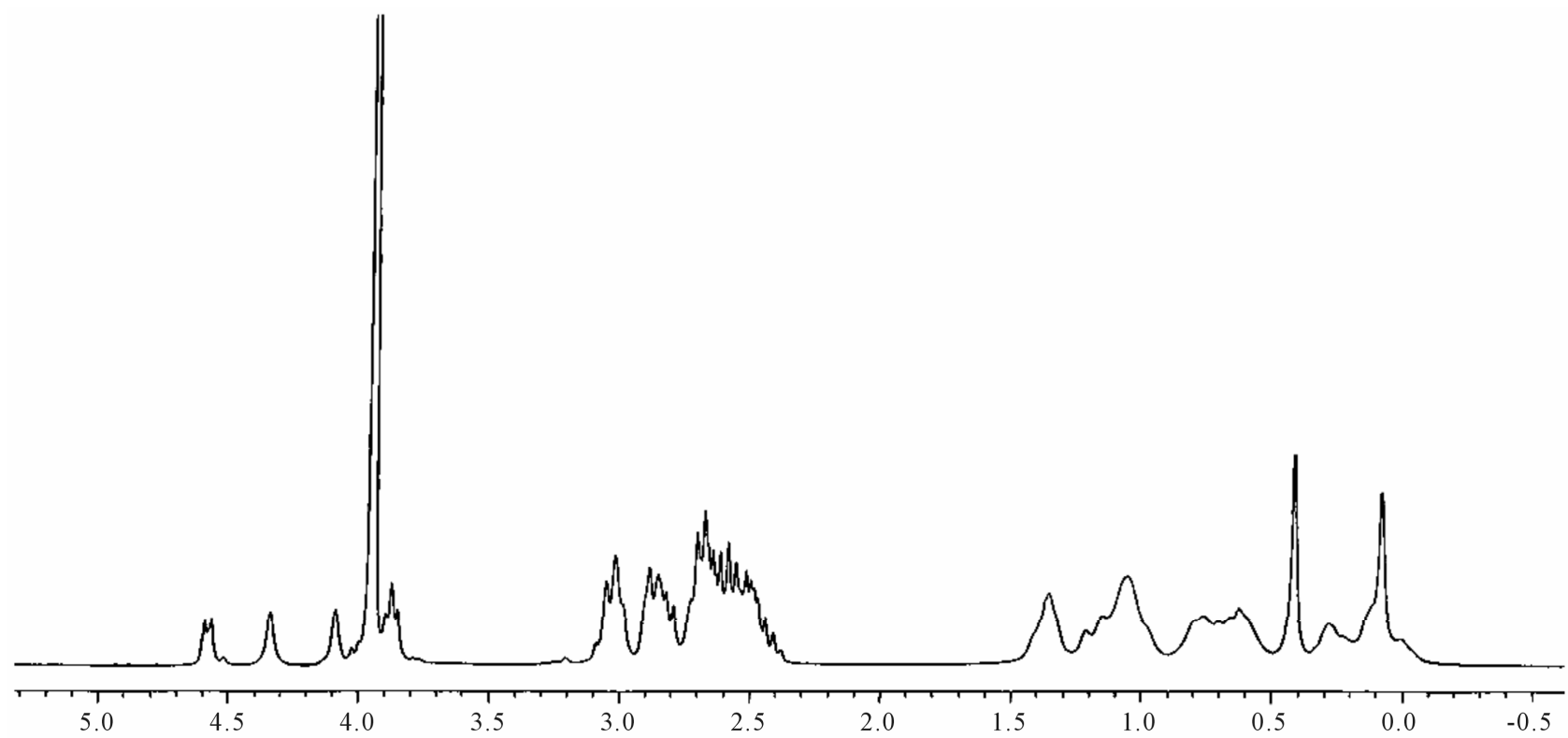

Figure 5. NMR spectra-pure stevioside.

procedure required in isolation of the steviol glycosides is a present day challenging problem. An object of the study is to develop a rapid and effective methodology of production of natural sweetener steviol glycosides and to overcome the disadvantages associated with extraction processes. The study establishes a continuous isolation of steviosides from the stevia leaves by integrated and simple clarification process using inexpensive membranes in removing color pigments, high molecular impurities and obnoxious residues. An enrichment of the steviosides could be obtained in permeate during clarification by UF process, as the UF membrane was sensitized by a coating of hydrophilic polyvinyl alcohol polymer which may have significant affinity towards retaining steviosides, leading to its preferential separation of impurities with a higher molecular weight. Finally, nano membrane filtration (NF) processes remove lower molecular weight impurities. There were no losses of steviosides in the 


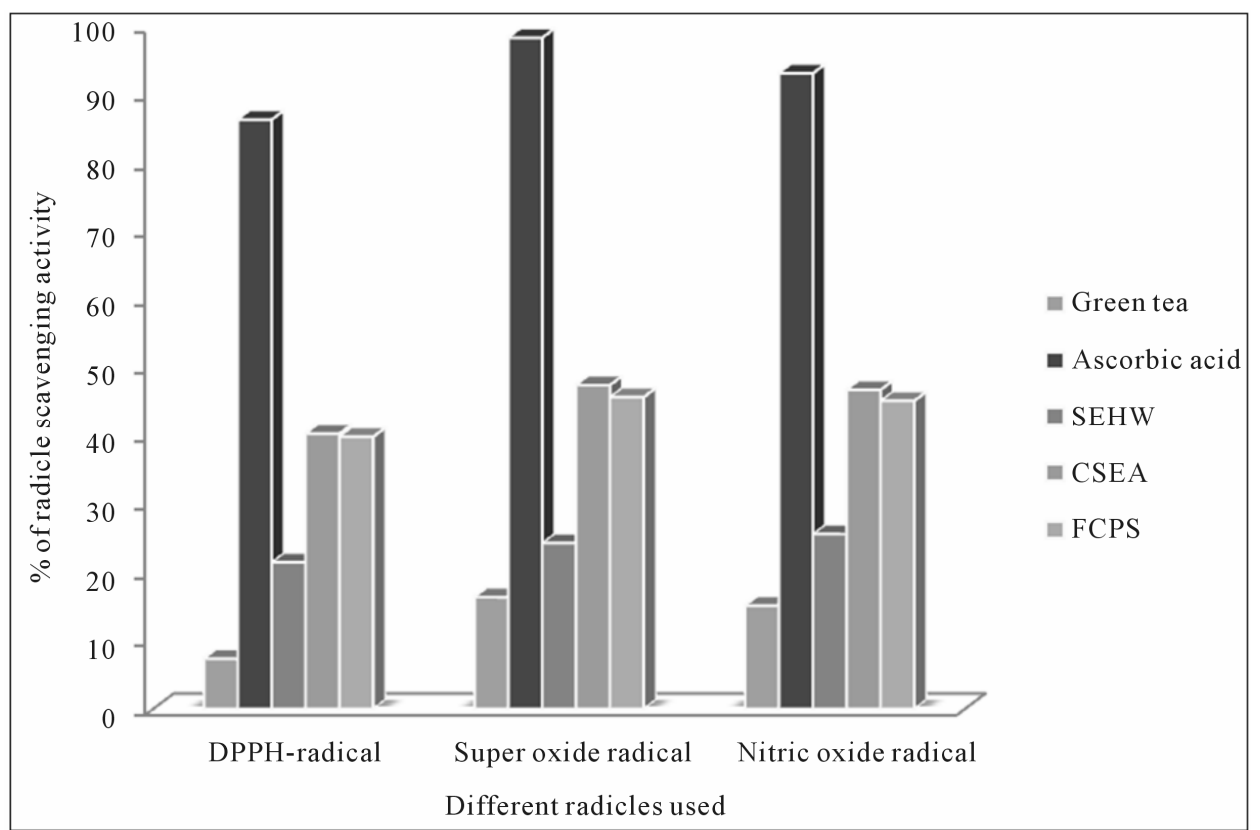

Figure 6. Comparative percentage of antioxidant activity of steviosides glycosides with sucrose in human volunteers. "SEHW-stevia leaf extract of hot water similar to that of Green tea extract. ${ }^{*} \mathrm{CSEA}$ crude stevia leaf extract after autoclave. *FCPS-final crystallized product of stevia leaf extract.

Table 2. Comparative sweetness and (bitter) no sweet after taste of steviosides glycosides with sucrose in human volunteers.

\begin{tabular}{|c|c|c|c|c|c|c|c|c|}
\hline \multirow{2}{*}{ S. No } & \multirow{2}{*}{ Samples } & \multirow{2}{*}{ Conc. (gm/lit) } & \multicolumn{3}{|c|}{ Exp-1: Test for sweetness } & \multicolumn{3}{|c|}{ Exp-2: Test for bitter; no sweet after taste } \\
\hline & & & Sweeter & Same & Weaker & Stronger & Same & Weaker \\
\hline \multirow{4}{*}{1} & \multirow{4}{*}{ Sucrose } & $20(\mathrm{R})$ & Ref & Ref & Ref & Ref & Ref & Ref \\
\hline & & 5 & 0 & 0 & 25 & 0 & 0 & 0 \\
\hline & & 20 & 1 & 23 & 1 & 0 & 0 & 0 \\
\hline & & 40 & 24 & 1 & 0 & 0 & 0 & 0 \\
\hline \multirow{6}{*}{2} & \multirow{6}{*}{ Commercial Stevioside } & 0.05 & 2 & 4 & 19 & 3 & 7 & 15 \\
\hline & & 0.1 & 15 & 8 & 1 & 16 & 8 & 1 \\
\hline & & 0.15 & 21 & 3 & 1 & 22 & 2 & 1 \\
\hline & & 0.2 & 24 & 1 & 0 & 25 & 0 & 0 \\
\hline & & 0.25 & 25 & 0 & 0 & 25 & 0 & 0 \\
\hline & & 0.3 & 25 & 0 & 0 & 25 & 0 & 0 \\
\hline \multirow{6}{*}{3} & \multirow{6}{*}{ FCPS (Extracted Stevioside) } & 0.05 & 3 & 5 & 17 & 2 & 5 & 18 \\
\hline & & 0.1 & 18 & 6 & 1 & 10 & 11 & 4 \\
\hline & & 0.15 & 23 & 2 & $\mathbf{0}$ & 16 & 6 & 3 \\
\hline & & 0.2 & 25 & $\mathbf{0}$ & $\mathbf{0}$ & 21 & 4 & $\mathbf{0}$ \\
\hline & & 0.25 & 25 & 0 & 0 & 24 & 1 & $\mathbf{0}$ \\
\hline & & 0.3 & 25 & 0 & 0 & 25 & 0 & 0 \\
\hline
\end{tabular}

The results given were the mean of 25 human volunteers. ${ }^{*}$ FCPS-final crystallized product of stevia leaf extract; ${ }^{*}$ Exp-1: in this two (Commercial and final crystallized product of stevioside) samples of steviosides are compared with sucrose for their sweetness. ${ }^{* *}$ Exp-2: in this two (Commercial and final crystallized product of stevioside) samples of steviosides are compared with sucrose for their (Bitterness) no sweet after taste. 
permeate during the NF process indicating $100 \%$ rejection; confirming the most of the steviol glycosides extracted from stevia leaves was recovered. The process also confirms the improved taste, palatability and antioxidant activity of the isolated steviol glycosides. Thus, this study established simple "green" method of extraction steviosides using multi-stage membrane based purification techniques in a viable, economical (saving time and energy) and eco-friendly conditions.

\section{ACKNOWLEDGEMENTS}

The authors are grateful for the financial support by Department of the Biotechnology, (DBT) New Delhi, Author G R express sincere thanks to DBT for awarding the research fellowship.

\section{REFERENCES}

[1] Gibbs, B.F. and Mulligan, C. (1996) Sweet and taste-modifying proteins: A review. Nutrition Research, 16, 16191630. doi:10.1016/0271-5317(96)00175-3

[2] Abou-Arab, A.E., Abou-Arab, A.A. and Abu-Salem, M.F. (2010) Physicochemical assessment to natural sweeteners steviosides produced from Stevia rebaudiana bertoni plant. African Journal of Food Science, 4, 269-281.

[3] Brahmachari, G., Mandal, L.C., Ray, R., Mondal, S. and Brahmachari, A.K. (2011) Stevioside and related compounds-Molecules of pharmaceutical promise: A critical overview. Archiv der Pharmazie-Chemistry in Life Science, 1, 5-19. doi:10.1002/ardp.201000181

[4] Chhya, Mondal, S., Majumdar, G.C. and De, S. (2012) Clarification of stevia extract using cross flow ultrafiltration and concentration by nanofiltration. Separation and Purification Technology, 89, 125-134. doi:10.1016/j.seppur.2012.01.016

[5] Gregersen, S., Jeppesen, P.B., Holst, J.J. and Hermansen, K. (2004) Anti hyperglycemic effects of stevioside in type 2 subjects. Metabolis, 53, 73-76. doi:10.1016/j.metabol.2003.07.013

[6] Chatsudthipong, V. and Muanprasat, C. (2009) Stevioside and related compounds: Therapeutic benefits beyond sweetness. Pharmacology \& Therapeutics, 121, 41-54. doi:10.1016/j.pharmthera.2008.09.007.

[7] Wolwer-Rieck, U., Tomberg, W. and Wawrzun, A. (2010) Investigations on the stability of stevioside and rebaudioside A in soft drinks. Journal of Agriculture Food Chemistry, 58, 12216-12220. doi:10.1021/jf102894v

[8] JECFA (Joint FAO/WHO Expert Committee on Food Additives) (2007) Evaluation of certain food additives and contominants. Sixty-eight report of the Joint FAO/WHO Expert Committee on Food Aditives. World Health Organization (WHO), Geneva, 50-54.

[9] Zhang, S.Q., Kumar, A. and Kutowy, O. (2000) Membranebased separation scheme for processing sweeteners from stevia leaves. Food Research International, 33, 617-620. doi.10.1016/S0963-9969(00)00098-3.

[10] Pól, P., Varadová Ostrá, E., Karásek, P., Roth, M., Bene- šová, K., Kotlaříková, P. and Čáslavský, J. (2007) Comparison of two different solvents employed for pressurised fluid extraction of stevioside from Stevia rebaudiana: Methanol versus water. Analytical and Bioanalytical Chemistry, 388, 1847-1857. doi:10.1007/s00216-007-1404-y

[11] Puri, M., Sharma, D., Barrow C.J. and Tiwary, A.K. (2012) Optimisation of novel method for the extraction of steviosides from Stevia rebaudiana leaves. Food Chemistry, 132, 1113-1120. doi:10.1016/j.foodchem.2011.11.063

[12] Teo, C.C., Tan, S.N., Yong, J.W.H., Hew, C.S. and Ong, E.S. (2010) Pressurized hot water extraction (PHWE). Journal of Chromatography A, 1217, 2484-2494. doi:10.1016/j.chroma.2009.12.050

[13] Fuh, W.S. and Chiang, B.S. (1990) Purification of stevioside by membrane and ion exchange processes. Journal of Food Science, 55, 1454-1457. doi:10.1111/j.1365-2621.1990

[14] Zhang, S.O., Kumar, A. and Kutowy, O. (2000) Membrane-based separation scheme for processing sweeteners from stevia leaves. Food Research International, 33, 617 620. doi:10.1016/S0963-9969(00)00098-3

[15] Li, J. and Chase, H.A. (2010) Applications of membrane techniques for purification of natural products. Biotechnology Letters, 32, 601-608. doi:10.1007/s10529-009-0199-7

[16] Vanneste, J., Sotto, A., Courtin, C.M., Van Craeyveld, V., Bernaerts, K., Van Impe, J., Vandeur, J., Taes, S., and Van der Bruggen, B. (2011) Application of tailor-made membranes in a multi-stage process for the purification of sweeteners from Stevia rebaudiana. Journal of Food Engineering, 103, 285-293.

doi:10.1016/j.jfoodeng.2010.10.026

[17] Puri, M., Sharma D. and Tiwari, A.K. (2011) Downstream processing of stevioside and its potential applications. Biotechnology Advances, 29, 781-791. doi:10.1016/j.biotechadv.2011.06.006

[18] Pasquel, M.A.A., Meireles, M.O.M., Marques, and A.J. Petenate (2000) Extraction of stevia glycosides with $\mathrm{CO}_{2}$ water, $\mathrm{CO}_{2}$ ethanol, and $\mathrm{CO}_{2}$ water ethanol. Brazilian Journal of Chemical Engineering, 17, 271-282. doi:10.1590/S0104-66322000000300003

[19] Liu, Y., Di, D., Bai, Q., Li, J., Chen, Z., Lou, S and Ye, H. (2011) Preparative separation and purification of rebaudioside A from steviol glycosides using mixed-mode macroporous adsorption resins. Journal of Agricultural and Food Chemistry, 59, 9629-9636. doi:10.1021/jf2020232

[20] Kutowy, O., Zhang, Q.S. and Kumar, A. (1999) Extraction of sweet compounds from Stevia rebaudiana Bertoni. US Patent No. 5972120.

[21] Midmore, J.D. and Rank, A.H. (2006) An intense natural sweetener laying the ground work for s new rural industry. RIRDC Publication 06/020 RIRDC Project No UCQ17A.

[22] Silva, F.V., Bergamasco, R., Andrade, C.M.G., Pinheiro, N., Machado, N.R.C.F., Reis, M.H.M., de Araujo, A.A. and Rezenede, S.L. (2007) Purification process of stevioside using zeolites and membranes. International Journal of Chemical Reactor Engineering, 5, 1-6.

[23] Abelyan, V.H., Ghochikyan, V.T., Markosyan, A.A., Adam- 
yan, M.O. and Abelyan, L.A. (2010) Extraction separation and modification of sweet glycosides from Stevia rebaudiana plant. US Patent No. 7838044B2.

[24] Aruoma, O.I. (1994) Nutrition and health aspects of free radicals and antioxidants. Food and Chemical Toxicology, 32, 671-683 doi:10.1016/0278-6915(94)90011-6

[25] Kehrer, J.P. (1993) Free radicals as mediators of tissue injury and diseases. Critical Reviews in Toxicology, 23, 21-48.

[26] Devasagayam, T.P.A., Tilak, J.C., Boloor, K.K., Sane, K.S., Ghaskadbi, S. and Lele, R.D. (2004) Free radicals and antioxidants in human health: Current status and future prospects. Journal of the Association of Physicians of India, 52, 794-804.

[27] Williams, G.M., Latropoulos, M.J. and Whysner, J. (1999) Safety assessment to butylated hydroxyanisol and btylated hydroxytoluene as antioxidant food additives. Food and Chemical Toxicology, 37, 1027-1038. doi:10.1016/S0278-6915(99)00085-X

[28] Yanishlieva, N.V., Marinova, E. and Pokorny, J. (2006) Natural antioxidants from herbs and spices. European Journal of Lipid Science and Technology, 108, 776-793. doi:10.1002/ejlt.200600127

[29] Aneta, W., Jan, O. and Renata, C. (2007) Antioxident activity and phenolic compounds in 32 selected herbs. Food Chemistry, 105, 940-949. doi:10.1016/j.foodchem.2007.04.038

[30] Shukla, S., Mehta, A., Mehta, P. and Bajpai, V.K. (2011) Antioxident ability and total phenolic content of aqueous leaf extract of Stevia rebaudiana Bert. Experimental and Toxicological Pathology, 39, 183-200. doi:10.1016/j.etp.2011.02.002

[31] Huang, X.Y., Fu, J.-F. and Di, D.-L. (2010) Preparative isolation and purification of steviol glycosides from Stevia rebaudiana bertoni using high-speed counter-current chromatography, Separation and Purification Technology, 71, 220-224. doi:10.1016/j.seppur.2009.11.025

[32] Gardana, C.M., Scaglianti, M. and Simonetti, P. (2010) Evaluation of steviol and its glycosides in Stevia rebaudiana leaves and commercial sweetener by ultra-high-performance liquid chromatography-mass spectrometry. Journal of Chromatography A, 1217, 1463-1470. doi:10.1016/j.chroma.2009.12.036

[33] Horwitz, W. (2000) Official methods for analysis. AOAC International, Gaithersburg.

[34] Sridhar, S., Ravindra, R. and Khan, A.A. (2000) Recovery of monomethyl hydrazine liquid propellant by per evaporation method. Industrial \& Engineering Chemistry Research, 39, 2484-2488. doi:10.1021/ie990776c

[35] Cardello, H.M.A.B., Da Silva, M.A.P.A. and Damasio, M.H. (1999) Measurement of the relative sweetness of stevia extract, aspartame and cyclamate/saccharin blend as compared to sucrose at different concentrations. Plant Foods for Human Nutrition, 54, 119-129. doi: 10.1023/A:1008134420339

[36] Schiffman, S.S., Pecore, S.D., Booth, B.J., Losee, M.L., Carr, B.T., Sattely-Miller, E., Graham, B.G., Warwick, Z.S. (1994) Adaptation of sweeteners in water and in tannic acid solutions. Physiology \& Behavior, 55, 547-59. doi:10.1016/0031-9384(94)90116-3

[37] Lu, M., Yuan, B., Zeng, M. and Chen, J. (2011) Antioxidant capacity and major phenolic compounds of spices commonly in China. Food Research International, 44, 530-536. doi:10.1016/j.foodres.2010.10.055

[38] Parpinello, G. P., Versari, A., Castellari, M. and Galassi, S. (2001) Stevioside as a replacement of sucrose in peach juice: Sensory evaluation. Journal of Sensory Studies, 16, 471-484. doi:10.1111/j.1745-459X.2001.tb00314.x

[39] Halliwell, B., Gutteridge, J.M. and Aruoma, O.I. (1987) The deoxyribose method: A simple "test tube" assay for determination of rate constants for reaction of hydroxyl radicals. Analytical Biochemistry, 165, 215-219. doi.10.1016/0003-2697(87)90222-3

[40] Devasagayam, T.P.A. and Kamat, J.P. (2002) Biological significance of singlet oxygen. Indian Journal of Experimental Biology, 40, 680-992.

[41] Kaur, C. and Kapoor, H.C. (2002) Anti-oxidant activity and total phenolic content of some Asian vegetables. International Journal of Food Science \& Technology, 37, 153-161. doi:10.1046/j.1365-2621.2002.00552.x

[42] Jain. D.P., Pancholi S.S. and Patel, R. (2011) Synergistic antioxidant activity of green tea with some herbs. Journal of Advanced Pharmaceutical Technology \& Research, 2, 177-183. doi:10.4103/2231-4040.85538

[43] Schertz, F.M. (1928) The quantitative determination of chlorophyll. Plant Physiology, 3, 323-334.

[44] Murthy, G.S., Sridhar, S., Shyam Sunder, M., Shankaraiah, B. and Ramakrishna, M. (2005) Concentration of xylose reaction liquor by nanofiltration for the production of xylitol sugar Alcohol-Part-II. Separation and Purification Technology, 44, 221-228.

[45] Van der Bruggen, B., Manttari, M. and Nystrom, M. (2008) Draw backs of applying nanofiltration and how to avoid them: Review. Separation and Purification Technology, 63, 251-263. doi:10.1016/j.seppur.2008.05.010

[46] Khalaf, N.A., Shakya, A.K., Al-Othman, A., El-Agbar, Z. and Farah, H. (2008) Antioxidant activity of some common plants. Turkish Journal of Biology, 32, 51-55.

[47] Brand-Williams, W., Cuvelier, M.E. and Berset, C. (1995) Use of a free radical method to evaluate antioxidant activity. LWT-Food Science Technology, 28, 25-30. doi:10.1016/S0023-6438(95)80008-5 